\title{
Del autor junta palabras al autor junta palabras, imágenes, sonidos, interactividades, algoritmos: la gestión literaria en la era (post) digital*
}

Fecha de recepción: 8 de febrero de 2018

Fecha de aprobación: 15 de mayo de 2018

\section{Resumen}

Entender la literatura como gestión del lenguaje, la información y la comunicación, abre perspectivas relevantes para asumir los retos que la eclosión mediática contemporánea le plantea a sus diversos ejercicios. Este artículo propone un recorrido que pasa por cuatro momentos diferenciados por la evolución de los modos de comunicación, que se ha acelerado casi frenéticamente en los últimos años. La literatura como gestión de ciertas dinámicas textuales, la literatura como gestión intermedial, la literatura como escenario expandido de la ficción dada la extensión de las prácticas de una cultura digital y la literatura como ejercicio post digital. Este recorrido se convierte, al final, en un espacio que se puede transitar sincrónicamente, gracias a un mapa que ofrece una cartografía conceptual que invita a un viaje de exploración por las transformaciones del paisaje cultural de hoy, cada vez más complejo y rico.

Palabras clave: literatura expandida; intermedialidades; post digitalismos; algoritmos literarios.

Citar: Rodríguez Ruíz, J. A. (enero-junio de 2018). Del autor junta palabras al autor junta palabras, imágenes, sonidos, interactividades, algoritmos: la gestión literaria en la era (post) digital. La Palabra, (32), 19-41. doi: https://doi. org/10.19053/01218530.n32.2018.8159.

\section{Jaime Alejandro Rodríguez}

Profesor de la Pontificia Universidad Javeriana, Bogotá. Investigador asociado Colciencias. Doctor en Filología. UNED (España).

jarodri@javeriana.edu.co

*Artículo de reflexión resultado de investigación: 1) Narratopedia: diseño, desarrollo y puesta online de una plataforma virtual para la narración digital colectiva (2011), 2) Simulador I.C. un escenario transmedial de pruebas para la simulación de inteligencia colectiva (2014), y 3) Memorias y caminos: Plataforma hipermedial para ejercicios autobiograficos (2016). 


\section{Abstract}

Understanding literature as language, information and communication management opens relevant perspectives with regards to the challenges posed by the contemporary media outbreak. This paper proposes a journey through four moments, differentiated by the evolution of communication modes and their frantic acceleration in recent years. Literature as management of certain textual dynamics; literature as intermedial management; literature as expanded scenario of fiction -given the extent of digital culture practices-, and literature as post-digital exercise. In the end, this tour becomes a space to be traveled synchronously, a map that offers a conceptual cartography inviting an exploratory journey through the transformations of today's increasingly complex and rich cultural landscape.

Keywords: Expanded literature; Intermedialities, Post digitalisms; Literary algorithms

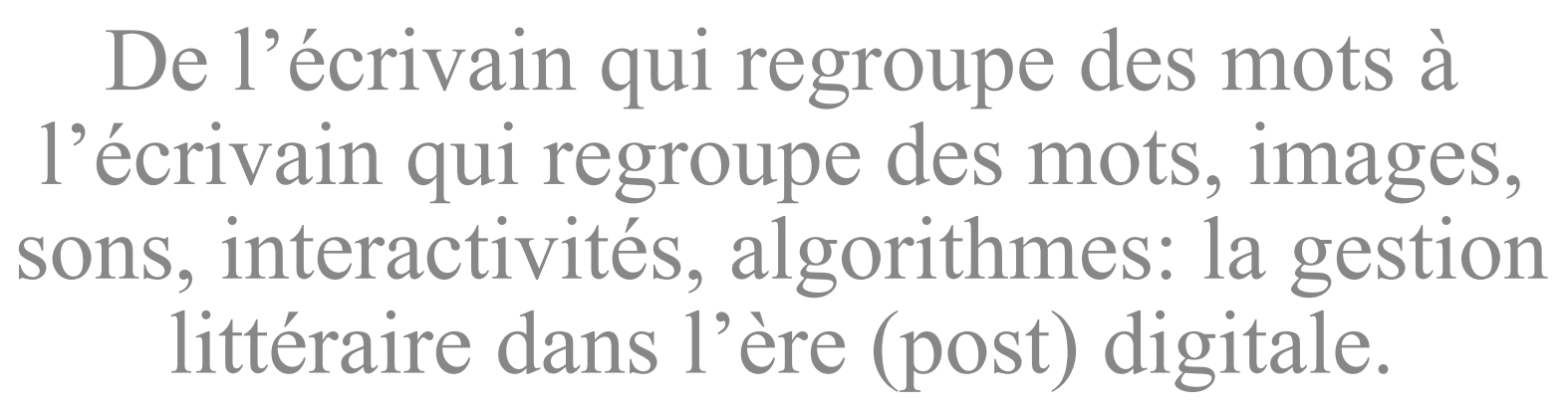

\section{Résumé}

L'éclosion métiathique de nos jours est un véritable défi pour l'exercice littéraire. Comprendre la littérature comme gestion du langage, de l'information et la communication permet de construire de nouvelles perspectives. Dans cet article nous proposons un parcours des quatre moments differenciés par l'évolution des modes de communication, qui s'est accelérée frénétiquement dans les dernières années. La littérature comme gestion de certaines dinamiques textuelles, la littérature comme gestion intermédiale, la littérature comme une scène élargie de la fiction étant donné l'amplitude des pratiques de la culture numérique et la littérature comme exercise post digital. Ce parcours, devient, à la fin, un espace qui peut-être traversé synchroniquement à partir d'une carte qui propose une cartographie conceptuelle et qui invite à un voyage d'exploration des transformations du paysage culturel de nos jours, de plus en plus complèxe et riche. 
Mots-clés: littérature experimentale; intermédialités; post numérisation; algorhitmes littéraires.

\section{A modo de introducción}

Vivimos transformaciones muy fuertes a nivel social y cultural derivadas de la emergencia y extensión de las llamadas tecnologías digitales. No se trata solamente de contar con otros medios o posibilidades de expresión, sino que todo el sistema comunicativo y en particular el literario se ha venido afectando dramáticamente: el lector se ha convertido en lecto-espectador (Mora, 2012) e incluso en lector-espectador-internauta (García Canclini, 2009) configurando toda una cultura post-lectora (Piscitelli, 2009). El libro ha dejado de ser el principal soporte de contenidos, y sus sucedáneos han generado prácticas y formas de producción y creación inéditas que han cambiado definitivamente el paisaje artístico y cultural. La novela ha dejado de ser la forma de ficción privilegiada y tiene que competir cada vez más con artefactos como los videojuegos y las nuevas formas audiovisuales e interactivas.

El proceso de des-hegemonización de las formas escriturales, que comenzó con el advenimiento y crecimiento del cine $\mathrm{y}$ de la televisión, se ha extendido gracias al poder de los nuevos dispositivos interactivos. En este ambiente, los creadores literarios se ven enfrentados a tres alternativas: mantienen y defienden formas tradicionales de hacer literatura, con el peligro de "aislar" definitivamente la práctica literaria; migran o mutan a otros escenarios más vinculados con las posibilidades que han abierto las nuevas condiciones socio técnicas; reinventan finalmente el ejercicio literario, incorporando, a su modo, los contenidos, las problemáticas y las formas expresivas mismas de la sociedad contemporánea.

En el título de mi propuesta, uso una expresión que extraje de un artículo que escribió el español Jorge Carrión (2016) al día siguiente de la entrega del Premio Nobel de Literatura a Bob Dylan. Carrión habla allí de dos tipos de figuras literarias, una que él llamó en su artículo como el junta-palabras vinculada al escritor tradicional que hace poesía, teatro, novela e incluso crónica o testimonio, y la otra que amplía el término hacia las alternativas de futuro para la literatura: el autor, junta-palabras, sonoridades, algoritmos, lúdicas e interactividades ${ }^{1}$, tratando de recoger en él un poco lo que es hoy un panorama muy amplio de las posibilidades de escritura creativa en Europa, Estados Unidos y muy posiblemente también en nuestro medio, que no es inmune a estas tendencias globales.

Hablo en el título también de gestión y no de creación, porque he descubierto un libro que fue traducido como Escrituras no-creativas, pero que corresponde más bien a la idea de una escritura sin creación (uncreative writings) o a una escritura sin compromiso con el imperativo de la originalidad, y que se subtitula precisamente: Gestión del lenguaje en la era digital. La idea de su autor, Kenneth Goldsmith (2015), es que la literatura debe entenderse como gestión del lenguaje, como un ars combinatoria de recursos informáticos y comunicativos, que para un cierto momento histórico se fundó en la escritura alfabética, sus géneros y estructuras, pero que hoy incluye el lenguaje de los medios masivos $\mathrm{y}$, más recientemente, las gestiones que permiten las tecnologías digitales.

\section{La literatura como gestión de dinámicas textuales}

El asunto de la gestión tiene que ver, en últimas, con el modo como se organiza el mensaje que, para el caso del momento histórico previo a la aparición de los medios masivos y de las

En Bejarano (2016) podemos ver como este giro en el concepto de escritor y obra literaria empieza a impulsarse desde las vanguardias del s. XX, con poetas como Mallarmé. Por su parte, Borrero (2012) señala la multiplicidad de caminos y posibilidades que se abren al visionar la literatura como un campo expandido. 
tecnologías digitales, corresponde a lo que la teoría ha estudiado como géneros, estructuras y funciones literarias. La narratología, por ejemplo, ha identificado unas estructuras específicas, basadas en las posibilidades de relacionar recursos como el narrador, los personajes, las representaciones del tiempo, del espacio y de las voces, y que en general corresponden a dinámicas textuales (Ong, 1997) que se aprovechan para generar o provocar un sentido, una sugestión o una posible dimensión trascendente de ese mensaje, a través de una operación estética que nos hemos acostumbrado a llamar obra literaria.

Un aspecto vinculado a esta perspectiva de entender la literatura como gestión del lenguaje alfabético, es el de la opacidad del sistema, correspondiente a una división del trabajo. Es decir, lo que se nos enseña o lo que se nos pide a los escritores es (únicamente) escribir: desarrollar bajo las dimensiones canónicas o preceptivas de la literatura, un resultado original de las combinatorias posibles de esas preceptivas, pero nunca nos preguntamos por las otras dimensiones del sistema literario entendido como un sistema, que no solo se basa en la escritura y en la producción de obras, sino que incluye a los lectores que las reciben, las maneras como se publican y venden (Guzman y Marín, 2016; Marín, 2017; Vigna, 2016), y los modos en que se enseña la literatura (Bolivar y Gordo, 2016; Altamirano, 2016)., y los modos en que se enseña la literatura. Eso, quizás, hace que parte del diseño y gestión de una obra literaria quede un poco en esa oscuridad obligada por la división del trabajo. La idea subyacente en esta perspectiva es: "dedíquese a escribir que nosotros (los otros actores del sistema) nos dedicamos a producir la obra materialmente, a divulgarla, a enseñarla, etc.”.

Otro aspecto que tiene que ver con esta perspectiva de la producción textual, es el recurso en los talleres de creación a referencias estéticas, historiográficas y poéticas, como claves para el aprendizaje de técnicas literarias; y el uso de teorías críticas como marcos conceptuales para la creación (Saavedra 2017; Brijaldo 2014) que finalmente terminan constituyendo muchas de las bases de los procesos de formación en escritura creativa. Todo esto puede verse como una primera forma de entender la literatura: como gestión del lenguaje escrito, sus estructuras y sus dinámicas sociales.

\section{La literatura como gestión de medios: intermedialidades}

Pero podemos caracterizar un segundo momento en el que deberíamos hablar del paso de una gestión del lenguaje a una gestión de medios. Hay estudios actuales, tanto en el campo teórico como creativo, llamados intermediales que revisan justamente los diversos fenómenos de relación entre un medio y otro: posibilidades, cercanías o lejanías.

El campo de la intermedialidad atiende la influencia mutua, la correlación o la interacción entre dos o más prácticas significantes, donde ninguna de ellas posee mayor jerarquía que la otra y que puede generar una redefinición de cada uno de los medios o prácticas implicadas, así como nuevas formas de percepción de estos medios o prácticas. En términos académicos, esto implica la construcción de espacios de diálogo entre distintas prácticas significantes o procesos artístico-culturales.

De las muchas maneras de entender la intermedialidad, seguimos aquí a Irina Rawjesky (citada por Cubillo, 2013), quien se interesa en analizar las especificidades de los diversos fenómenos intermediales y establece tres categorías de intermedialidad, que resultan muy cercanas a lo que desarrollo más adelante desde una perspectiva personal:

1) Intermedialidad como transposición medial (por ejemplo, las adaptaciones de películas o las novelizaciones): aquí la calidad intermedial tiene que ver con la forma en la que un producto mediático llega a existir, es decir, con la transformación de un determinado producto 
mediático (un texto literario, una película) o de su substrato en otro medio. Existe un texto "original", que es la "fuente" del recién creado medio; se da un proceso de transformación de un medio.

2) Intermedialidad como combinación de medios: se combinan medios como el cine, el teatro, los performances, las instalaciones de arte, los cómics y otros, es decir, prácticas "tradicionales" se mezclan con los multimedia o incluso con medios asociados a las nuevas tecnologías; cada medio aporta su propia materialidad y ambos contribuyen a constituir y a significar el nuevo producto. Se pasa de la pura contigüidad de dos o más manifestaciones materiales a una "verdadera" integración.

3) Intermedialidad como referencialidad a otros medios, por ejemplo, las referencias en un texto literario a una película o viceversa, o bien la evocación de ciertas técnicas cinematográficas en la literatura (el zoom, los fundidos, los encadenados, el montaje o la edición). Otros ejemplos podrían ser la llamada musicalización de la literatura, la ekfrasis, las referencias a la pintura en una película o bien en la pintura a la fotografía, y así sucesivamente. En esta categoría, en lugar de combinar diferentes formas mediales de articulación, un medio dado evoca, tematiza o imita elemen- tos o estructuras de otro medio convencional (Rajewsky, 2005, p. 44).

Estos estudios constituyen un campo de trabajo muy interesante. Voy a señalar, por lo menos, cuatro formas de gestión de medios que he utilizado en mi propia obra (como detallaré más adelante) y lo voy a centrar más en la dimensión narrativa, o en la dimensión de creación de mundos posibles: la remediación, la hipermediación, la transmediación y la literatura expandida.

La remediación es un ejercicio que consiste en llevar una obra originalmente hecha en un medio a otro medio. El ejemplo clásico es cuando se lleva una obra literaria al cine. Hoy tendríamos también la obra literaria que es llevada al cómic, al videojuego, a la realidad virtual, etc., y este ejercicio juega en ambos sentidos.

La hipermediación, en cambio, es juntar todos los medios. Es lo que antes se llamaba multimedia, solo que esta vez integra la interactividad, es decir, la obligación del usuario de recorrer, de activar la obra para que ocurra.

La transmediación, por su parte, se refiere a aquellos proyectos que, desde el comienzo, imaginan una obra para ser desplegada en distintos medios o plata simultáneamente, aunque la producción no sea simultánea. Desde un comienzo, el proyecto transmedia prevé que, por ejemplo, una novela pueda tener su variación cinematográfica, en cómic, interactiva, etc. Adicionalmente, transmedia implica una especial naturaleza participativa. Scolari (2013), por ejemplo, ilustra la manera en que los consumidores construyen historias transmedia aprovechando el espacio que dejan los fragmentos narrativos, de maneras que difieren para el participante inmerso de aquellos que están más casualmente comprometidos. Neil Perryman (2008), por su parte, insiste en la potencia que da al universo transmedia la construcción interactiva del mundo de las historias. Elwell (2014) afirma que, en la forma ideal de la narración transmedia, cada medio hace lo que mejor sabe hacer, de modo que una historia podría ser presentada en una película, expandida a través de la televisión, novelas y cómics; su mundo podría ser explorado a través del juego o experimentado como una atracción de un parque de atracciones. No obstante, y a pesar de la sugerencia de una integración del universo narrativo, no es necesario haber visto la película para disfrutar del juego y viceversa. Elwell propone que los mundos transmedia son, a la vez, integrados, dispersos, episódicos e interactivos. Es decir, el modelo transmediático de la narración y la construcción de mundos estaría 
caracterizado por la integración de múltiples elementos de la historia que se dispersan a través de múltiples plataformas $\mathrm{y}$ medios en un formato episódico que permite la interacción de la audiencia co-creadora.

Está finalmente, la creación colectiva, que es básicamente la idea de cómo aprovechamos las redes y la interactividad para que sea un conjunto de autores y no solamente uno el que construya la obra. Seguramente, un trabajo tan complejo como la realización de un artefacto transmedia, implica que la creación sea colectiva, pero la creación colectiva puede emprenderse en escenarios menos complejos como la autoría múltiple o la expansión participativa de textos.

\section{La literatura expandida en} (por) la era digital

En un tercer momento, la relación más productiva se da entre el ejercicio del escritor tradicional y el ambiente que algunos comunicólogos han llamado de "eclosión mediática" (expansión de los modos de comunicación que va de la radio, al cine a la televisión y más recientemente, a las redes sociales y a las aplicaciones móviles). Correspondiente a esta situación, emerge un concepto concomitante: la "ecología de medios" (Scolari, 2015). Antes de la eclosión mediática, teníamos solamente la palabra o el audio- visual, cinematográfico o televisivo, y había una cierta relación de la literatura con esos medios, pero hoy ya tenemos todo un escenario súper amplificado a partir, justamente, de la extensión de las tecnologías digitales interactivas, de las posibilidades de las realidades ampliadas y de un gran repertorio de posibilidades expresivas que muchas veces se yuxtaponen ante la mirada atónita, incómoda, del escritor, una situación que he descrito antes en el artículo: Sueños digitales del escritor (2009) y que Skaines ha capitalizado en sus reflexiones sobre las transformaciones del proceso creativo.

En efecto, siguiendo a Skains (2016), hemos estado (al menos para el caso del dispositivo literario de ficción) culturalmente tan determinados por lo escritural como forma predominante de expresión, que hemos olvidado que nuestra imaginación, antecesora de la actividad creadora, es básicamente multimodal: concebimos historias con sonidos, olores, movimiento e imágenes que traducimos a una forma textual. Es más, la creación multimodal de obras, por lo general, consiste en una nueva traducción desde lo textual hacia los otros formatos. ¿Se necesita entonces desaprender este camino para hacer más fluida la composición multimodal? Tal vez sí, y tal vez estamos viviendo un momento favorable para este "reversazo": no solo habría una disposición más na- tural entre el consumo/producción de contenidos multimodales, sino que las herramientas para que lo concebido pueda pasar directamente a su(s) formato(s) correspondiente(s) están cada vez más disponibles.

Ahora, ¿cómo abordamos esa eclosión mediática? Como dije antes, los comunicólogos se han inventado ese otro concepto paralelo, que es la ecología de medios, una fórmula metafórica para proponer estrategias de convivencia de estos medios. Simultáneamente, surgen escenarios que reconocen la necesidad de relativizar a la literatura como única o al menos legítima fuente de ficciones.

En efecto, la literatura siempre ha sido y será por mucho tiempo el principal repositorio universal de la ficción, pero no es el único dispositivo ficcional, y ya hay estudios de todos los dispositivos ficcionales que cumplirían, eso sí respetando el carácter intrínseco de cada uno, la misma función de crear mundos posibles y de generar impactos y funciones cognitivas, estéticas y trascendentes a través de la ficción.

Por mucho tiempo, hemos creído que la escritura es el instrumento más potente de representación de la realidad, pero la escritura no la puede presentar, no hay un libro en el que se pueda escuchar las voces de los personajes, o un libro en el que 
uno pueda ver las acciones; lo que sí hay es un puente entre la escritura y la mente del lector, para que eso (escuchar, ver; incluso, oler y sentir) ocurra en ese ámbito: el mental. Entonces, se habla de una falsa volumetría del libro, que finalmente tiene una oportunidad real con esta eclosión de medios y esta posibilidad de juntarlos y gestionarlos.

Es en el marco de este orden de ideas que se hace legítimo y necesario hablar de la relativización de la literatura: considerarla como una más de las artes de la ficción. Siguiendo a Schaeffer (2002) y su planteamiento de los dispositivos ficcionales, la literatura haría parte de ese tipo de arte, el arte de la ficción, que se caracteriza por proponer efectos de inmersión a un lector que se dispone a aceptar un juego en particular, el juego del "como si". De este modo, las ficciones, según Schaeffer, garantizan sus tres funciones fundamentales: generar algún tipo de conocimiento (función cognitiva), generar gusto por el relato (función estética) y generar efectos de refiguración (función trascendente).

Schaeffer propone siete dispositivos ficcionales, cada uno de los cuales dispone un vector de inmersión (juego "como si" particular) y exige, a su vez, una postura de inmersión (implicaciones del lector o usuario). Los tres primeros dispositivos son quizá los más utilizados por las ficciones literarias (como si estuviera escuchando un narrador, como si estuviera escuchando las palabras y actos de habla de las personas protagonistas del relato, como si pudiera acceder a la mente de alguien). Los otros cuatro dispositivos se alejan de las posibilidades de la literatura: como si estuviera viendo algo real (pintura, fotografía), como si estuviera viendo-escuchando algo real en movimiento (cine, animación), como si estuviera observando un acontecimiento real (teatro), como si estuviera manipulando los acontecimientos (ficciones digitales interactivas).

Literatura amplificada, literatura transmediada, literatura enriquecida

La literatura, es cierto, ha desarrollado y cualificado a lo largo de varios siglos de práctica sociocultural sus estrategias de ficcionalización, llevando a niveles insospechados su particular poder de representación en complicidad, claro, con lectores que han aprendido a actualizar en su mente con mucha habilidad las imágenes de mundos posibles propuestos por el texto literario; sin embargo, su apuesta a esa pragmática tan dependiente del proceso comunicativo escritura/lectura, la inhabilita para incorporar procesos y efectos de percepción que otros medios han venido afinando recientemente como los que describe
Schaeffer (2002): la imagen, la animación audiovisual, la presentación de acontecimientos y la interactividad tecnológica. Es lo que Julia Kristeva alguna vez denunció como la falsa volumetría de la novela (Kristeva, 1974).

Para Kristeva, la pretensión fallida de la novela de dar cuenta de la totalidad de lo real (pretensión volumétrica, según sus palabras) inaugura lo que ella llama el espacio curvo de la comunicación. En efecto, la novela no presenta, no puede presentar la realidad (imposibilidad volumétrica), así que la re-presenta (espacio curvo), esto es, usa una plataforma que, de manera indirecta (escritura, lectura, entonces actualizacion mental del mundo posible sugerido), expone la realidad, muy en la línea escolástica de promover el esfuerzo mental antes que la experiencia perceptiva. La reivindicación contemporánea de la imagen y la sofistificacion tecnológica de los sistemas de presentación perceptual (Bolter, 1998), sin embargo, han vuelto a poner sobre la mesa las posibilidades de la presentación volumétrica (articulación de morfológicas como la palabra, la imagen fija y en movimiento, el audio, etc.) en un camino que, es la promesa, debería conducirnos a la realidad virtual; y esto abre la necesidad de pensar otra literatura, abre todo un campo de posibilidades intermediales e interdiscursivas que 
quiero desplegar a través de tres conceptos.

De un lado, el que se ha empezado a denominar como "literatura amplificada o expandida" y que consiste en afinar la mirada y en ampliar los marcos conceptuales de lo literario para empezar a incluir crítica y creativamente como "literarias", producciones de otros ámbitos como los cómics, las novelas gráficas, las hipernovelas, los videojuegos, los weblogs $\mathrm{y}$, en general, los artefactos que expanden el poder de lo ficcional, a través de distintas plataformas y medios. Esta alternativa implica extender la noción tradicional de lo literario hasta hacerla coincidir plenamente con lo que Scheaffer (2002) llama lo ficcional, es decir, implica entender la literatura como la ficción en general, implica entenderla como expresión volumétrica.

En segundo lugar, y para abordar el problema que consiste en rehacer (deconstruir) el discurso literario en función de las potencias comunicativas, técnicas y estéticas de los nuevos medios, propongo el término "literatura transmediada", que tiene en el concepto de "trasvase cinematográfico" un antecedente imprescindible, pero relativo a la hora de asumir esas transformaciones. Re-mediar, hiper-mediar, trans-mediar $\mathrm{y}$ crear colectivamente son apenas cuatro de las derivaciones necesarias de este ejercicio que exige una capacidad interdiscursiva e intersemiótica y una mirada práctica interdisciplinar que favorezca esa otra expansión de lo literario: su adaptación a la potencia de los medios interactivos.

Finalmente, propongo el término "literatura enriquecida", para cubrir esa literatura que capitaliza los hallazgos técnicos, estéticos y cognitivos de los nuevos medios en el ejercicio tradicional literario y que tiene aquí, de nuevo, un antecedente en la fuerza influenciadora de lo cinematográfico sobre la práctica narrativa literaria, pero que va más allá, hacia la búsqueda de nuevas potencias creativas y críticas para la escritura literaria tradicional, a partir de lo que emerge de la práctica estética concreta que se deriva de la comunicabilidad interpelativa de los nuevos medios.

Quizá, la mejor ilustración de lo que aquí llamamos literatura expandida es el festival Kosmopolis, que bienalmente se realiza en Barcelona (España), el Centro de cultura contemporánea. En la presentación de su página web, se lee:

En Kosmopolis la literatura es la protagonista en todas sus vertientes: apostamos por un concepto de literatura amplificada, en todas aquellas manifestaciones de la palabra -oral, impresa y electrónica- que erosionan las divisiones entre géneros, asumen la evolución de los soportes de lectoescritura y sortean las sucesivas muertes anunciadas. Desde su primera edición, Kosmopolis ha reunido a escritores, poetas, filósofos, científicos, músicos, cineastas, dramaturgos, cuentacuentos, dibujantes de cómic, guionistas, periodistas, actores, bibliotecarios y editores dispuestos a debatir sobre temas clave de nuestra actualidad y a celebrar un discurso universalista, una fiesta para emancipar lectores, estimular la mutación del canon, agitar los géneros, interactuar con las ciencias, navegar en lenguas y revisar mitos, tradiciones e identidades (http:// www.cccb.org/kosmopolis/ es/projecte).

Como se ve aquí, hay claramente una actitud que aprovecha de algún modo el nicho literario para abrir desde allí, desde el prestigio de lo literario, la práctica cultural a campos diversos. Lo amplificado es estratégico, es un modo de "sortear la muerte de la literatura" estableciendo alianzas con prácticas que, aunque técnica y materialmente diferentes, tendrían en común la textualidad, entendida de un modo amplio (evolución de los soportes de lecto/escritura). Palabra oral, impresa, electrónica y más recientemente, palabra audiovisual, se juntan en Kosmopolis, se hibridan, se autorreconocen y dialogan de forma extensa. 
Para ilustrar el concepto de literatura transmediada, quiero exponer brevemente, mi propia obra. Escribí mi ópera prima, la novela Gabriella Infinita, al final de los años ochenta (trabajaba entonces, tanto en el frente teórico crítico como en el artístico, la noción de posmodernidad) y la publiqué en 1994, convencido precisamente de haber logrado una obra posmoderna. Al final de aquel año, tuve la oportunidad de conocer los planteamientos de George Landow sobre hipertexto, y me di cuenta de que Gabriella debía ser un hipertexto.

Hacia el año 99, emprendí la tarea de reconvertir la novela en hipertexto y dos años más tarde, gracias a una beca del Ministerio de Cultura, ya como productor, reuní un equipo para transformarla en hipermedia. El testimonio de su creación (el artículo Del texto al hipermedia, 2004) fue incorporado a mi tesis doctoral: "El Relato digital", publicada en el año 2007.

Con el aprendizaje de la re-mediación (adaptación a hipertexto-media de una obra literaria) de Gabriella, emprendimos la tarea de desarrollar ya no una obra digital a partir de una obra literaria, sino un hipermedia desde sus condiciones intrínsecas (proceso de hipermediación como tal). El resultado fue Golpe de gracia en 2006, que tuvo un subproducto literario: la novela El infierno de Amaury. El siguiente reto, fue construir y dinamizar una plataforma ya no para albergar una obra, como para facilitar la intervención creativa de usuarios, es decir, para elevar el nivel de participación de los usuarios desde lo que Ryan (2004) llama interactividad selectiva a una interactividad participativa y creativa. El resultado de este trabajo recibió el nombre de Narratopedia, plataforma para la creación digital colectiva, la cual funcionó entre los años 2010 y 2015.

Al final del 2013, en el marco de una investigación sobre inteligencia colectiva, desarrollamos un ejercicio de transmediación de un texto literario, curiosamente un fragmento de Gabriella Infinita (Atrapados) que se convirtió a la vez en (web) cómic, en videojuego y en juego de rol. Con esto alcanzamos un final de ciclo que cubrió sucesivamente las cuatro formas de desarrollo de obras digitales interactivas que describí arriba: re-mediación, hipermediación, creación colectiva y trans-mediación.

Quiero ilustrar ahora el concepto de "literatura enriquecida", refiriéndome finalmente a tres jóvenes autores españoles de reciente reconocimiento, que han emprendido obras muy vinculadas a las prácticas mediáticas contemporáneas. Uno es Jorge Carrión, autor de una trilogía novelesca conformada por las obras Los muertos (2010), Los huérfanos (2014) y Los turistas (2015). En Los muertos, Carrión ofrece un texto escrito al modo del lenguaje de las teleseries, con tema y reflexión sobre este género televisivo, ambientado en un escenario ligeramente futurista, muy influenciado por prácticas culturales contemporáneos como las redes sociales, el medio del espectáculo y una geopolítica compleja.

Otra obra que puede incluirse en este marco es Alba Cromm, de Vicente Luis Mora (2010), novela que incluye el chat, el blog, el correo electrónico y la dinámica de las redes sociales, como parte y extensión del marco narrativo propio: una investigación de un caso de pederastia (relato policiaco). La obra de Mora presenta así, una serie de materiales que completan la historia y añaden nuevas perspectivas, es decir, desarrolla una estructura expandida por otros contenidos complementarios, Además, como aparece reflejado en el blog (ficticio, claro) que escribe la protagonista, los lectores (reales, claro) pueden acceder al universo ficcional de Alba Cromm a través de la novela $\mathrm{y}$, posteriormente, dirigirse a las entradas del blog para descubrir matices del personaje, o convertirse también en protagonistas del relato. Esta heterogeneidad del material (además del blog de Cromm, también está disponible el blog de Luis Ramírez el otro protagonista), obliga al lector a adop- 
tar los códigos de cada discurso $\mathrm{y}$, de algún modo, a abandonar los moldes de los géneros literarios para optar por el zapping.

Finalmente, quiero mencionar la novela Providence de Juan Francisco Ferré (2009). Una novela que adopta la estructura del videojuego (las partes se llaman niveles, por ejemplo, como las partes de los muertos se llaman temporadas), así como su lenguaje y una temática bastante truculenta que la aproxima a las dinámicas híbridas de la eclosión mediática contemporánea.

En Providence, un director cinematográfico se ve obligado a trabajar por primera vez en su carrera a partir de un guion que no es suyo. Pronto, descubrimos que el guion original se basa en una novela rusa que, a su vez, habla del caso enigmático de un videojuego con el que la desesperada dirigencia soviética de los años de la disolución trataban de ganar la mente de sus ciudadanos, trabajando así uno de los mitos sobre los videojuegos, según el cual, estos artefactos tienen el poder, más que otros, incluidos la literatura y el cine, de arrobar el alma y la mente de sus usuarios. Pero, aún más: en la novela se da que el videojuego sigue circulando clandestinamente ahora en Estados Unidos, en un ambiente que pronto convierte la novela, en una de sus tantas facetas, en thriller de espionaje deliciosamente truculento. La novela, según el propio autor, responde a una manera (muy posmoderna, por cierto), de sobrevivencia literaria: si la novela no tiene nada que hacer frente a artefactos ficcionales como el cine o el videojuego aclarar qué se está diciendo con esto, sí puede hacer de este hecho su tema y su reto estético. Providence y la obra de Ferré, en general, se configura así como una versión contemporánea de la literatura del agotamiento, propuesta $\mathrm{y}$ desarrollada en los años 70 por John Barth (1967).

\section{¿Una literatura post-digital?}

Un cuarto momento consiste en hablar de gestión de lenguajes y de la información en la era digital. Ahí es donde se hace relevante la propuesta de Goldsmith de las escrituras sin creación, e incluso la idea de unas escrituras post-digitales, porque ya no estamos en la era digital sino en la era post-digital, entendida como el tiempo donde lo digital y sus prácticas se han naturalizado y, por tanto, son objeto de uso cotidiano extendido. Básicamente, la idea de los autores que acuden al término post-digital es que, hoy por hoy, ya no dividimos el mundo en análogo y digital, en tradicional e interactivo, sino que se superan esas dicotomías, tanto en la creación como en el uso y aplicaciones contenidos en los distintos dispositivos y soportes.
Debemos recordar que la década de los noventa estuvo llena de anuncios optimistas en relación con lo digital, especialmente para las posibilidades artísticas. Quizás uno de los mejores ejemplos de confianza en lo digital para el mundo artístico más contundente, sea ese "Manifiesto" que Steven Holtzman propuso en su libro Digital Mosaics. The aesthetics of cyberspace (1997). En la introducción a su libro de 1997, en pleno momento de la euforia digital, Holtzman planteaba la necesidad de desprenderse de modelos teóricos y prácticos referidos a una manera de pensar que no correspondía a la de los mundos digitales. Lo digital empezaba a irrumpir en la cotidianidad, pero aún no se desarrollaban conceptos y habilidades que permitieran soltar los lazos con el pasado. Holtzman afirmaba que la práctica del rediseño y reciclaje de documentos y obras del pasado analógico a obras digitales, configuraba una actitud temerosa que no facilitaba la necesaria ruptura con lo tradicional, y por eso consideraba que el reciclaje y reformateo de obras era apenas una estrategia de transición, había que asumir entonces la superación de ese mundo hacia nuevos mundos de expresión.

Cuando Holtzman se refería a los mundos digitales, los definía como mundos que surgían renovando las imágenes mentales de otros mundos, y los caracteriza- 
ba como aquellos que solo pueden existir en el ciberespacio, es decir, en ese lugar imaginario localizado completamente en el dominio digital. Para Holtzman, los mundos digitales no eran los mundos naturales, sino mundos artificiales hechos por seres humanos y computadores. Esos mundos tenían, según el anuncio de Holtzman, el potencial para expresar ideas sorprendentes y emociones profundas de una manera que ningún otro medio de expresión humana podía hacer. Los mundos digitales no podían existir sin el computador y no podían ni siquiera concebirse fuera de la tecnología digital.

Holtzman brindaba en su libro una especie de guía del viajero digital, describiendo algunas obras y objetos realizados por artistas pioneros y por investigadores que empezaban ya a potenciar todas las dimensiones de estos mundos. Holtzman era consciente de que, en su momento, era imposible hablar de obras maestras digitales, pero advertía que empezaban a vislumbrarse algunos de los caminos que tendrían éxito, tales como el arte del fractal, la escritura virtual, la expresión a través de vida artificial animada en computador, las experiencias musicales interactivas, etc.

En realidad, los mundos digitales todavía estaban en su infancia y solo el desarrollo de las herramientas poderosas que estaban en camino, permitiría apreciar toda la riqueza por venir. Holtzman confiaba plenamente en que los instrumentos digitales extenderían muy pronto la expresión humana hacia cosas que antes no se podían comunicar y que se descubrirían mundos espectaculares, inimaginables antes de la invención del computador. El descubrimiento de esa "alma" de la cultura digital, afirmaba, reformaría incluso la lógica con la que, entonces, pensábamos.

Pues bien, toda esa confianza, toda esa seguridad, encontraría en su concreción un desvío interesante en lo post digital. Post digital, en el ámbito del discurso de la práctica artística digital, es un término que apunta precisamente a dar cuenta de las relaciones cambiantes entre las tecnologías digitales y las formas de arte, recuperando explícitamente la preocupación por el ser humano frente a lo que se venía proponiendo, siguiendo a Negroponte, el imperativo de $E l$ ser digital.

Kim Cascone inventa el término post digital en su artículo The Aesthetics of Failure: "Post-digital" Tendencies in Contemporary Computer Music (2002) (La estética del fracaso: tendencias "post-digitales" en la música de computadora), acudiendo curiosamente a otra expresión de Nicholas Negroponte: "La revolución digital ha terminado" Wired, (1998). Cascone, en particular, cree que géneros como el glitch o el microsound music son signos de una actitud post digital clara y advierte que el medio de la tecnología digital en sí mismo ha dejado de fascinar a los compositores.

En The Future of Art in a Postdigital Age (2002) (El futuro del arte en una era postdigital), Mel Alexenberg define "arte postdigital" como obras de arte que abordan la humanización de las tecnologías digitales a través de la interrelación entre sistemas digitales, biológicos, culturales y espirituales, entre el ciberespacio y el espacio real, entre los medios analógicos y los mundos digitales, entre la comunicación social y la física, entre la alta tecnología y las experiencias táctiles, entre las experiencias de los medios visuales, hápticos, auditivos y cinestési$\cos$, entre realidad virtual y aumentada, entre autoetnografía y narrativa comunitaria. El propio Alexenberg produjo lo que él llamó wikiart, obras de arte creadas con medios alternativos a través de la participación, la interacción y la colaboración en la que se redefine el papel del artista.

En Art after Technology (2002) (El Arte después de la Tecnología), Maurice Benayoun enumera posibles pistas para el arte "post-digital". El autor observa cómo la alteración del paisaje social, económico y artístico, ocasionado por la presencia 
masiva del medio digital, ha obligado al artista a moverse intentando escapar del ámbito tecnológico sin poder descartarlo completamente. Así, emergen nuevas formas que van del lowtech a la biotecnología y la fusión crítica -la inclusión crítica de la ficción dentro de la realidad-, pasando por obras que juegan con una relación digital / colaboración física.

Un término que podría ser equivalente al de post digital, es el de post Internet. Según Juan Martín Prado, en su artículo Sobre el arte post Internet (2017), hay una suerte de práctica artística que comienza al final de los años 90 y se hace más evidente en tiempos más recientes, que básicamente tematiza los efectos de la expansión del uso de la red tecnológica, pero haciéndolo mediante manifestaciones plásticas tradicionales. Bajo este término, se quiere reconocer que las prácticas artísticas más recientes se desarrollan no solamente vía online sino también offline. Prácticas artísticas que, independientemente del medio utilizado, estarían tomando la red y sus efectos como tema central de sus propuestas, en ocasiones descritas como poéticas de la conectividad.
Algunos ejercicios literarios post digitales

Asumir la naturalidad y transparencia de lo digital, plantea como reto hacer de las prácticas de la gestión de información digital, una oportunidad estética. Hoy, cuando escribimos un texto usando el procesador de palabras, estamos en realidad gestionando códigos de programación que además potencian esa escritura para acciones como la replicación, la edición, el corte y pegue de fragmentos, la movilidad de los textos y otras acciones que la digitalización facilitan. En la siguiente imagen (opciones de edición que la aplicación de google docs ofrece) se muestran algunas de esas acciones.

La barra horizontal ofrece herramientas de edición micro textual que permiten enriquecer el texto (acciones tipográficas, correcciones ortográficas, inserción de elementos) y en la barra vertical de la derecha se ofrecen acciones para gestionar el texto integral (copiar, mover, compartir, explorar el código, explorar el texto, dar formato, etc.).

A partir de estas consideraciones, voy a ofrecer ahora una muestra de ejercicios literarios postdigitales. En primer lugar, los ejercicios "goldsmithianos" como los correspondientes a las apropiaciones. Por ejemplo: 1) transcribir un texto literario aje- no y presentarlo y defenderlo como propio, indicando qué de la expresión propia podría justificar esa "autoría"; 2) usar el traductor de google para traer al castellano una pieza literaria breve de un idioma desconocido y "arreglar" el texto, manipularlo hasta hacerlo legible y correspondiente a la expresión propia; 3) desarrollar un texto con las "resonancias" (secretas correcciones, comentarios, imágenes recreadas) que produzca un texto literario ajeno (remake), dejando el título y las partes estructurales intactas.

Otro ejercicio es el de las recontextualizaciones. Por ejemplo: tomar nota, registrar o copiar un texto de alguna situación narrativa no literaria (presentación en audiencia jurídica de un caso, noticia televisiva, memorando de oficina, decretos, etc.) y leerlo ante una audiencia como si de una pieza literaria se tratara.

También, se incluyen en estos ejercicios las distintas intertextualidades. Por ejemplo: 1) tomar un texto literario ajeno y reelaborarlo, siguiendo alguno de los treinta y dos (32) modos de la intertextualidad previstos por Roberto Vélez en su texto: "Misterios y encantos de la intertextualidad (1990); 2) "Blanquear" páginas de un libro de literatura (pintar de blanco o cubrir con hojas blancas) y escribir a mano un texto nuevo sobre las páginas pintadas o sobre las 
cubiertas en blanco, haciendo el esfuerzo de recordar y acercarse lo más posible al texto original (palimpsesto).

También, se puede ensayar toda una amplia gama de ejercicios apócrifos: desarrollar textos imitando el estilo de un autor o crear la figura autoral. Un ejemplo famoso recientemente es la elaboración de Vicente Luis Mora del número 322 de la revista española Quimera. Toda la revista fue escrita por Mora, imitando el estilo literario de autores reconocidos que "firmaron" los artículos o inventando nombres para otros autores, en un verdadero ejercicio de miscelánea y ventriloquia literaria, realmente admirable.

Otro ejercicio cabría en el rótulo de remediaciones inversas: ver una película, jugar un videojuego, leer un cómic y fabricar una escaleta narrativa $o$ un relato literario a partir de esa experiencia. Esta re-mediación es inversa, pues volvemos a la escritura a partir del consumo de un medio y no al revés. Un ejercicio impresionante de este tipo es la novela La saga de los Marx de Luis Goytisolo (2013), en la que la nieta de Carlos Marx, en compañía de su propia abuelo, contemplan, comentan, re-narran toda la secuencia telenoticiosa que dió cuenta de la caída del Muro de Berlín en 1989 y que significó la caída del realismo social imaginado por Marx. Aquí, el medio (noticiero televisivo) se vuelve escritura literaria.

Los ejercicios post digitales frecuentemente recurren a la creación colectiva, justamente por su natural alejamiento a las condiciones de autoría original. Un ejemplo podría ser que un grupo se cite virtualmente (cada miembro del grupo desde su lugar personal) para ver, en tiempo real, una película o serie televisiva y teniendo abierto un chat grupal, re-narrar colectivamente lo visto, y luego tomar el texto obtenido de esa manera, editarlo también colectivamente hasta obtener un texto literario íntegro.

Otro ejercicio colectivo consiste en usar una aplicación de escritura colaborativa (google docs, por ejemplo) para desarrollar un texto de manera virtual en condiciones sincrónica, bajo reglas de actuación predefinidas como turnos o restricciones de intervención, tiempos de duración, etc.
Otro tipo de gestiones digitales consiste en manipular e intervenir código de audio y/o de imagen, y producir efectos de esta "escritura". Un ejemplo interesante de este tipo fue la obra de David Hall, presentada en el Festival del IV Congreso de la ELO (Electrónic Literature Organization): "A Brief History of Loss", cuyo registro puede visualizarse en https://youtu.be/ wHuJ3SvMe5U. En esta obra, el autor presenta en vivo a su audiencia, un ejercicio desplegado en tres ventanas de la pantalla del computador, donde lo desarrolla en tiempo real. En la ventana izquierda, hay una foto antigua tipo álbum familiar, donde aparece una mujer acompañada de su pequeña hija. En la ventana central, inicialmente en blanco, el autor escribe un relato que narra la pérdida que significó para la niña la muerte de su madre. En la tercera ventana, está el código correspondiente a la imagen digital de la ventana de la izquierda. Los espectadores pueden ver cómo el autor empieza a manipular el código y su efecto en la imagen, que consiste en que la foto se va "borrando" de abajo hacia arriba, creando el efecto de la desaparición no solo de la imagen, sino de las personas representadas. 


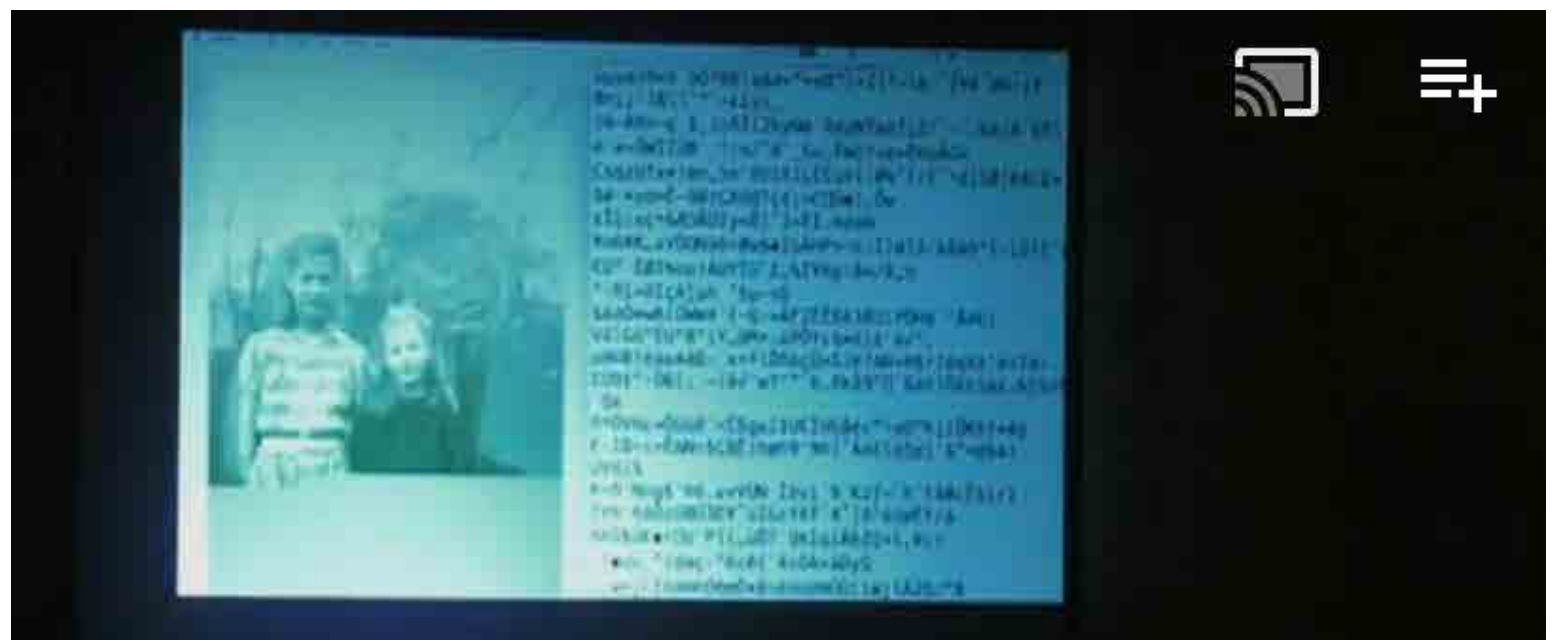

Figura 1. Manipulación del código en "A Brief History of Loss".

Otro ejercicio que resalta con énfasis Goldsmith, es el de la literatura conceptual. Escribir no relatos, sino fórmulas o instrucciones o predicados narrativos, que deben ser desarrollados por otros escritores a la manera del arte conceptual que estuvo tan de moda en los años sesenta del año pasado.

Muy en la tónica de la escritura no comprometida con la originalidad,esto consiste en demostrar que ninguna historia o narración es totalmente original (derrota de la originalidad): imaginar una historia muy singular; luego, revisar en internet hasta encontrar si hay o no una pieza ya hecha que se acerque a esa idea; y elaborar por escrito todo el proceso de búsqueda.

Las narrativas in situ o ficción en presente, son también ejercicios que aprovechan las facilidades digitales. Se trata de transmitir en vivo y en directo, historias que están ocurriendo al momento de la transmisión, ya sea transmitiendo texto, audio y también vídeo-stream.

Quizá el concepto que puede englobar mejor todas estas prácticas es Remix. Justamente Knobel \& Lankshear (2011) hablan del Remix como la nueva escritura popular. Algunos ejemplos que proponen los autores, son: remezclar fragmentos de video de diferentes películas para crear tráilers falsos de películas inventadas; ambientar los fragmentos de las películas remezcladas con música (a ser posible también remezclada) sincronizada con la acción visual; grabar una serie de dibujos animados japoneses y editar el video al ritmo de una canción de moda; mezclar imágenes "fusionadas" con imágenes originales, para expresar un tema o una idea (con o sin texto); o mezclar imágenes, animaciones y textos, para crear viñetas (in- cluyendo viñetas de corte político o animaciones).

Con este recorrido hecho hasta aquí, he querido ilustrar cómo la literatura a lo largo de la historia cambia si se la entiende como estrategias de gestión del lenguaje con el propósito de generar efectos interpelativos. Lo importante a destacar es que esas formas de gestión cambian, pero no desaparecen, sino que más bien se superponen y ofrecen una ampliación de las posibilidades literarias. Sin embargo, la velocidad con la que está gestión se transforma crea y justifica la sensación o la tendencia a no considerar como literatura los últimos tres momentos descritos (el momento mediático, el momento digital y el momento post digital). Sin embargo, Pero esos caminos no solo están en marcha, sino que son irreversibles. 
Más transformaciones a la vista

\section{¿Algoritmos literarios?}

Hay otras muchas transformaciones que se pueden visualizar desde la perspectiva de la gestión de lenguajes, como la que podemos llamar el giro algorítmico del pensamiento-creación. Se trata de entender que, finalmente, lo que hace un autor cuando logra su estilo es crear un algoritmo literario, porque el estilo de un escritor es un tipo de algoritmo, es decir, responde a ciertas dinámicas, secuencias e instrucciones y formatos, si bien implícitos, rastreables y reconocibles.

Hace poco, compré un libro que se llama Si Hemingway hubiera escrito un Java Script (2017). Java Script es un lenguaje de computación que, según dicen los programadores, es lo más cercano al lenguaje literario en términos de posibilidad de escribirlo con estilo propio y alcanzar así una expresividad singular. El libro mencionado hace un análisis de veinte autores, entre ellos dos latinoamericanos, y presenta el algoritmo literario de cada uno (con base en una muestra de su obra), es decir, la forma algorítmica con la cual cada uno se puede identificar. Finalmente, hace un ejercicio: un breve programa en Java Script que "traduce" la muestra textual en algoritmo.

Aquí, un ejemplo de esta singular estrategia analítica:

Ernest Hemingway's work is characterized by direct, uncomplicated prose and a lack of artifice. In his fiction, he describes only the tangible truths: dialog, action, superficial traits. He does not attempt to explain emotion; he leaves it alone. This is not because Hemingway doesn't want his stories to convey feeling - quite the opposite: his intent is to create a vacuum so that it might be filled by the reader's own experience. After all, emotion is more easily felt than described with words:

I have tried to eliminate everything unneces-sary to conveying experience to the reader so that after he or she has read something it will become a part of his or her experience and seem actually to have happened.

Hemingway's prose is never showy, and his syntax is almost obsessively conventional. The short, unchallenging sentences and absence of difficult words add a childlike quality to his cadence. $\mathrm{He}$ assumes the role of naive observer, all the better to draw his readers into the emotional chaos beneath. ${ }^{2}$

$2 \quad$ Traducción libre del fragmento:

El trabajo de Ernest Hemingway se caracteriza por su prosa directa, sin complicaciones y ausencia de artificios. En su ficción, él describe solo las verdades tangibles: diálogo, acción, rasgos superficiales. Lo hace sin intentar explicar la emoción. No porque Hemingway no quiera transmitir sentimientos en sus historias, todo lo contrario: su intención es crear un vacío para que pueda ser llenado por la propia experiencia del lector. Después de todo, la emoción se siente más fácilmente que la descrita con palabras: He intentado eliminar todo lo innecesario para transmitir la experiencia al lector de modo que después de que él o ella haya leído algo lo hará convertirse en parte de su experiencia y parece que realmente sucedió.

La prosa de Hemingway nunca es llamativa, y su sintaxis es casi obsesivamente convencional. Las oraciones cortas, indiscutibles y la ausencia de palabras difíciles agregan una cualidad infantil a su cadencia. Él asume el papel de observador ingenuo, para mejor atraer a sus lectores al caos emocional subyacente. 


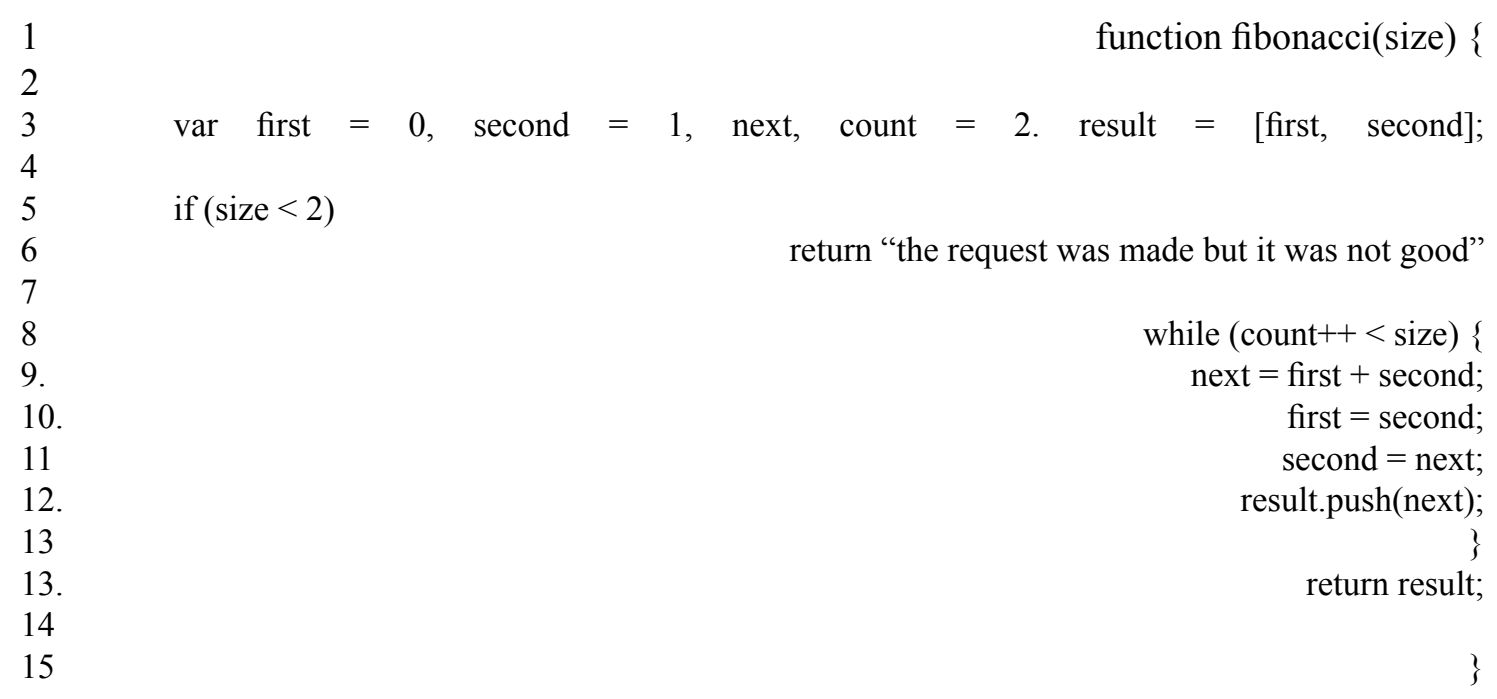

The Hemingway paradox is, to some extent, the JavaScript paradox. Just as Hemingway uses only the sparest prose to allow the intricacies of the human condition to surface, JavaScript's terse and direct syntax, when used well, can crystal lize complex logic into something tangible and immediate. Hemingway's Fibonacci solution is code reduced to its essentials, with no word or variable wasted. It's not fancy-maybe it's even a little pedantic - but that's the beauty of Hemingway's writing. There's no need for elaborate logic or showy variable names.
Hemingway's JavaScript is plain and clear, and it does only what is necessaryand then it gets out of the way to allow the full glory of the Fibonacci sequence to shine through.Hemingway didn't suffer fools gladly, so if you ask for a series with fewer than two numbers, he'll just ignore you or complain, "I'm tired and this question is idiotic." 3

Lo que propone Angus Croll (2015) para este caso, es que la escritura de Hemingway se acerca al estilo y efectos de la serie de Fibonacci. La serie Fibonacci es una sucesión infinita de números naturales que co- mienza con los números 0 y 1 , y a partir de ellos, cada término se obtiene sumando los dos anteriores:

$0,1,1,2,3,5,8,13,21,34,55$, $89,144,233,377,610,987$, $1.597 \ldots$

Se trata de una operación muy sencilla (sumar dos números), pero que en unas cuantas iteraciones empieza a producir resultados impresionantes, como el mostrado arriba: en menos de 20 iteraciones de la operación llegamos al número 1600. Así es la escritura de Hemingway, según Croll: hecha de operaciones literarias sencillas, cuyo acumulado va impactando en el

$3 \quad$ Traducción libre del fragmento:

La paradoja de Hemingway es, hasta cierto punto, la paradoja de JavaScript. Así como Hemingway usa la prosa más escasa para permitir la emergencia de las complejidades de la condición humana a la superficie, la sintaxis directa y concisa de JavaScript, cuando se usa bien, puede convertir la lógica compleja en algo tangible e inmediato.

La solución de Fibonacci de Hemingway es como código re enfocado en lo esencial, sin palabras ni variables vanas. No es elegante, tal vez es incluso un poco pedante, pero esa es la belleza de la escritura de Hemingway. No hay necesidad de una lógica elaborada o de nombres llamativos para las variables. El java script de Hemingway es simple y claro, y solo hace lo necesario, y luego se sale del camino para permitir la gloria completa de la serie de Fibonacci y brillar a través de ella. Hemingway no sufrió de gustos tontos, así que si pides una serie con menos de dos números, él simplemente te ignorará o se quejará: "Estoy cansado y esta pregunta es idiota". 
lector hasta sumergirlo en mundos humanamente emocionales muy complejos.

Lo curioso es que la serie de Fibonacci aparece repetidamente en la naturaleza y, además, tiene numerosas aplicaciones en ciencias de la computación, matemáticas y teoría de juegos, entre otras. Es decir, hay un algoritmo literario en Hemingway correspondiente a la forma como la naturaleza nos lleva de lo simple a lo complejo.

Está apareciendo así, una manera de reenfocar lo que hemos hecho siempre como lectores: reconocer patrones lingüísticos, simbólicos y semánticos; pero también como escritores: forjar nuestro propio patrón expresivo. Que veamos y llamemos esto algoritmo, no debería ser considerado un exabrupto o un sacrilegio, sino una oportunidad para ver y comprender mejor lo que hasta hace no mucho achacábamos a las musas.

\section{Nuevas lógicas de producción literaria}

En el ámbito de lo digital surgen y se favorecen nuevas lógicas de producción: está necesariamente el arte colaborativo, los equipos interdisciplinares, intermediales (me gustaría hablar más de intermediales que de interdisciplinares, para no combinar la disciplina y el arte), la auto-publicación y los circuitos interactivos de lectores-escritores. En el Diplo- mado de Escritura Creativa de la Javeriana, en el cual he sido profesor durante varias formaciones, hay una cosa muy interesante y es que, sobre todo en las últimas versiones, he probado usar redes como Wattpad, para ampliar la posibilidad de acción de las clases.

Es en los nuevos circuitos en donde funcionan las relaciones globales de escritores y de lectores que son nuevas formas de producción. El crowdfunding es una manera de financiación de proyectos complejos, donde se pide contribución (algunos llaman a estas contribuciones: micro mecenazgos) para iniciativas bien formuladas, con objetivos claros y una producción programada correctamente, y esta resulta ser una estrategia muy interesante. En general, se dan unas condiciones que yo llamo de transparencia sistémica, a diferencia de la opacidad del sistema cuando se hace solamente escritura.

\section{Más allá de la originalidad}

Volviendo a Goldsmith, su propuesta es que ya es imposible ser original, y que lo que hacemos es recombinar, apropiar, contextualizar, hacer intertextualidades, transcripciones $\mathrm{y}$ una cantidad de ejercicios donde lo que surge es la expresión. Eso es lo que hoy queda vivo, y no necesariamente ese imperativo de la originalidad, que es un imperativo moderno. Lo más clásico se renueva en el hiper- texto, el hipermedia, las novelas colectivas, la realidad virtual y el escenario transmedia o transmedial?. Hay muchos trabajos en Twitter y Blogs, están las estructuras post-literarias, como las mencionadas arriba y también lo que Doménico Chiappe llama las hiperfonías, una capa adicional a la polifonía literaria lograda con la escritura.

\section{Nuevos géneros}

Hay un blog en francés (literatures numériques, dirección electrónica), que recoge muestras de nuevas formas de expresión y nuevos géneros literarios. No aparecen allí cuentos, ni novelas, ni crónicas; aparecen ejercicios como animación de texto, creaciones colectivas, generación automática de textos, instalaciones literarias, código de juego, literatura hipertextual y literatura participativa. También se habla hoy de electro-poesía, xxxxx y otros ejercicios que son dimensiones resultantes de esa otra forma de gestión más reciente de la información y los lenguajes.

\section{Nuevos soportes: Libroides}

También aparecen y se requieren nuevos soportes, muy en la perspectiva de lo que exigen los lectores espectadores como un diálogo de materialidades.

Siguiendo a Fumero \& Roca (2007), una de las barreras que impiden un camino abierto a las 
transformaciones en curso, es la sensación de intangibilidad que producen las experiencias digitales. El entramado tecnológico, cada vez más complejo, que sustenta a la red pasa desapercibido o es demasiado complejo para la capacidad sensorial del ciudadano normal. Lo que ya se conoce como "la piel electrónica de la Tierra", afirman Fumero \& Roca, resulta invisible para el usuario que se conecta a la Red utilizando su PC o su teléfono móvil. La ilustración más clara de esta propiedad es la aparente desmaterialización bajo la que se esconde la considerable complejidad tecnológica de un instrumento técnico como es ese mismo ordenador personal:

La propia tecnología se muestra como un dominio cerrado para el usuario no especialista. Es, de hecho, el súper-usuario quien se erige como tecno-influenciador y figura clave detrás de la emergencia que se produce en la Web. Todos los servicios, herramientas, sistemas y plataformas que hacen realidad eso que llamamos la Web dos cero adolecen, a pesar de la "apertura" característica del software libre en que se sustentan, sigue siendo algo 'temible' para el inmigrante digital medio (Fumero \& Roca, 2007, p. 31).

Pues bien, una salida post digital a esta intangibilidad, sería un diálogo de materialidades que permitiera superar esa brecha de lo intangible. Osmo (2015) es una propuesta de entretenimiento que combina las actividades con materiales propios de las manualidades con las potencias digitales de las aplicaciones y programas del computador. En los videos promocionales de esta empresa, se ven niños que trabajan manualidades clásicas como armar rompecabezas o dibujar sobre papel o hacer algún tipo de texto, pero, frente a sus plataformas de trabajo físico, hay un computador dotado con una cámara que va "leyendo" esas acciones físicas y las va "traduciendo" en formas y efectos digitales en la pantalla. En el kit llamado "coding", por ejemplo, una niña coloca sobre la mesa de trabajo bloques de piezas físicas con apariencia similar a los bloques que se usan en programas como scratch, para aprender a codificar software. El computador traduce las acciones físicas de la niña en acciones en la pantalla con el efecto digital correspondiente (el que solo puede ocurrir en la pantalla), en este caso, la animación digital de paisajes. Osmo (2015) ofrece cada vez más variedad de juegos, todos bajo la idea de recuperar el goce del trabajo manual, cuyas acciones tienen además una potenciación digital.

Este diálogo de materialidades empieza a darse muy claramente en el ámbito editorial, específicamente para lo que el profesor Álvaro Llosa ha llamado
Libroides (2016), una especie híbrida del libro que juega justamente con la articulación del libro impreso y sus materiales, con las posibilidades que hoy se han abierto en el ámbito digital, justamente para superar la improductiva dicotomía entre ebook vs. libro impreso, y explorar más bien distintas posibilidades de articulación e hibridación.

Algunos ejemplos que nos ofrece Llosa son muy ilustrativos de este campo post digital: en primer lugar, el proyecto (ya cerrado) de la colección de Ediciones B, "librinos" inspirada en la idea de un editor holandés de Biblias, que buscaba publicar largas novelas en un formato pequeño y apaisado, con lo que la página impresa par e impar se leen sin pasar de página, a manera de pantalla de ordenador o rollo antiguo. Si bien esta forma de imprimir no es una novedad absoluta, el hecho de plantearla como una colección de libros de éxito en un contexto donde leemos cada vez más apasionadamente en las pantallas, plantea al menos una reflexión acerca de las limitaciones de las remediaciones digitales e impresas que parecen haber inspirado el proyecto editorial en el año 2009 en Holanda, y en el año 2012 en España. El segundo ejemplo de Llosa es ese "libro-artefacto" escrito por Jorge Carrión y publicado por vez primera en 2009, después actualizado en su formato en 
2014. En su última y más depurada versión, consiste en un libro impreso en formato apaisado que se asemeja a un ordenador portátil: cada hoja superior supone ver una pantalla con el contenido que habitualmente encontramos en internet tras una búsqueda, y cada hoja inferior supone ver el teclado con el que hacemos dicha búsqueda. La remediación aquí se ofrece con una gran coherencia, afirma Llosa, en el que fondo y forma se integran a la perfección, pues es la historia de la búsqueda de los orígenes de los Carrión a través de tres generaciones del narrador, la recuperación de la memoria a través de las facilidades de un Google claramente parodiado: álbumes de fotos familiares, mapas con rutas, "videos", entradas de blog, etc. Si bien la interactividad no funciona como lo hace un computador, su imitación produce un diálogo creativo, abierto y conciliador sobre las formas y los formatos posibles de la narración en un universo cultural híbrido, que se relaciona mucho con lo impreso como medio literario, a veces oponiéndolo a cualquier otro, pero que está acostumbrado cada vez más a comunicarse mediante los medios digitales.
En tercer lugar, Llosa expone el phonebook, un artefacto que integra una pantalla dentro de un libro impreso para ampliar la experiencia de lectura con material audiovisual, demostrando cómo dos objetos con códigos diversos, el impreso y el digital, buscan una simbiosis, en la que ya nos posible decidir cuál es la prótesis del otro, en un esfuerzo por dar respuesta a esa tensión social de poder e influencias que se vive entre ambos medios. En cuarto lugar, Llosa hace mención a algunos ejemplos particulares del uso de códigos QR en libros impresos y su extensión a través de la realidad aumentada, que genera una relación complementación muy potente para cada medio, y en la que cada uno aporta aquello que hace mejor cuando convergen, estableciendo una dependencia mutua y flexible entre contenidos y medios para desentrañar la experiencia completa de lectura mientras esta dura.

\section{A modo de conclusión}

Estamos abocados a cambiar, a incorporar de forma sensata y productiva lo que los medios no escriturales empiezan a en- señarnos que puede ser la literatura. Se trata de sumar a una responsabilidad con el pasado y la tradición, la responsabilidad con el futuro, y por esa razón es importante llamar la atención sobre lo que implica pensar y asumir las nuevas transformaciones.

A modo de conclusión, invito al lector a estar atento a estas y otras transformaciones del ejercicio literario. He preparado un mapa de recursos que amplían lo hasta aquí descrito.

En esta URL se puede acceder a dicho mapa: https://drive.google.com/file/d/1_XzxxG9HjEqgUSazo4tmgrJ $\bar{J}_{\mathrm{V}} \mathrm{XaIG}-\mathrm{YsL} /$ view? $\mathrm{usp}=$ drivesdk

La invitación concreta consiste en "planear" por ese mapa, ya sea siguiendo la secuencia de los momentos que he caracterizado aquí, o de manera aleatoria, mejor de manera aleatoria, como lo haría una mosca que sobrevolara ese posible territorio. 


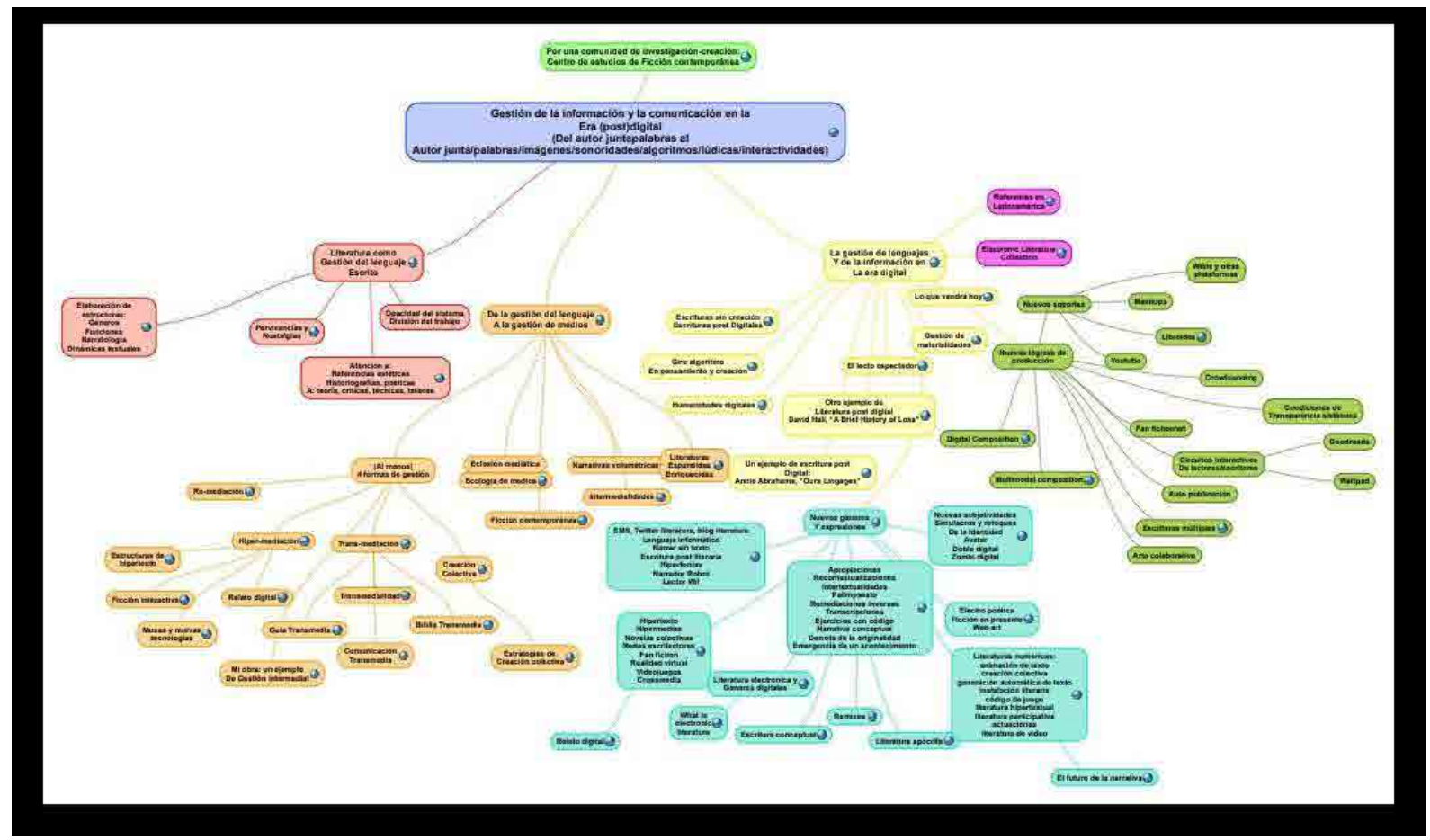

Figura 2. Mapa de recursos. Literatura como gestión del lenguaje.

Qué mejor motivación para ese viaje, que estas palabras de Michelle Serres (1994):

Es como el vuelo de una mosca: pasa en zigzags apresurados, entrecortados, discontinuos, cambia de rumbo de forma imprevisible, cruza de repente toda la habitación, de un extremo de la sala al aparador más alejado, en trayectos breves, medianos o largos, como si decidiera tirando los dados, se detiene, gira ampliamente sin alejarse demasiado, tropieza con obstáculos cercanos o contiguos, cristal, espejo, lámpara, mesa, trepida en una jaula, da vueltas en una pequeña isla, vuelve a partir... y ahora se escapa por la ventana abier- ta. Si entra por sorpresa en un automóvil o en un avión, se encontrará en el otro extremo de la Tierra, donde recomenzará su danza que creíamos alocada, pero que expone, maravilla de las maravillas, la razón y la sabiduría del mundo. (p. 97).

Vuela como una mosca, a lo mejor te harás sabio como ella. 


\section{Referencias}

Altamirano Flores, F. (enero-junio de 2016). Didáctica de la literatura: ¿cómo se contagia la literatura? La Palabra, (28), 155-171.

Barth, J. (1967). La literatura del agotamiento. The Atlantic Monthly, 220 (2), 170-182.

Bejarano, A. (julio-diciembre de 2016). Poéticas del intruso. Jacques Rancière, lector de Mallarmé. La Palabra, (29), 129-137.

Brijaldo Olarte, G. (enero-junio de 2014). Interpretaciones íntimas sobre la escritura performativa. La Palabra, (24), 111-117.

Bolívar Calixto, C.P., \& Gordo Contreras, A. (julio-diciembre de 2016). Leer texto literario en la escuela: una experiencia placentera para encontrarse consigo mismo. La Palabra, (29), 199-211.

Carrión, J. (2010). Los muertos. Barcelona: Random House Mondadori.

Carrión, J. (2016). Bob Dylan, ¿el primer nobel del futuro? Recuperado de https://www.nytimes.com/ es/2016/10/13/bob-dylan-el-primer-nobel-del-futuro/

Croll, A. (2015). If Hemingway wrote javascript. San Francisco: No Starch Press, Inc.

Cubillo Paniagua, R. (2013). La intermedialidad en el siglo XXI. Diálogos. Revista Electrónica de Historia, 14 (2), 169-179. Recuperado de https://revistas.ucr.ac.cr/index.php/dialogos/article/ view/8444/11465

Elwell, J. S. (2014). The transmediated self: Life between the digital and the analog. Convergence, 20 (2), 233-249. Recuperado de http://con.sagepub.com/content/20/2/233

Ferré, J. F. (2009). Providence. Barcelona: Anagrama.

Fumero, A., \& Roca, G. (2007). Web 2.0. Madrid: Fundación Orange. Recuperado de http://www.oei.es/ salactsi/WEB_DEF_COMPLETO2.pdf

García Canclini, N. (2007). Lectores, espectadores e internautas. Barcelona: Gedisa.

Goldsmith, K. (2015). Escritura no-creativa: gestionando el lenguaje en la era digital. (A. Page, trad.). Buenos Aires: Caja Negra.

Goytisolo, M. (2013). La saga de los Marx. Barcelona: Galaxia Gutemberg. 
Guzmán Méndez, D.P., \& Marín Colorado, P.A. (julio-diciembre de 2016). Lectores y textos escolares durante la primera mitad del siglo XX en Colombia. La Palabra, (29),185-197.Holtzman, S. (1997). Digital Mosaics. The aesthetics of cyberspace. New York: Touchstone.

Knobel, M., \& Lankshear, C. (2011). Remix: la nueva escritura popular. Revista Cuadernos comillas, 1, 105-126.

Kosmopolis. (s.f.). La fiesta de la literatura amplificada. Recuperado de http://www.cccb.org/kosmopolis/es/

Kristeva, J. (1974). El texto de la novela. Barcelona: Editorial Lumen.

Llosa, Á. (2016). El libro que quería ser máquina digital. Remediación y fisicidad en el Cuerpo del libro. Recuperado de http://hdh2015.linhd.es/ebook/hdh15-llosa.xhtml

Marín Colorado, P. (julio-diciembre de 2017). Reseña: Sapiro, Gisèle. (2016). La sociología de la literatura. La Palabra, (31), 191-195.

Mora, V. L. (2010). Alba Cromm. Barcelona: Seix Barral.

Mora, V. L. (2012). El lectoespectador. Barcelona: Seix Barral.

Ong, W. J. (1997). Oralidad y escritura. Tecnologías de la palabra. México: FCE.

Osmo. (2015). About us. Recuperado de https://www.playosmo.com/en/about-us/

Perryman, N. (2008). Doctor Who and the convergence of media: a case study in 'transmedia storytelling'. Convergence: The International Journal of Research into New Media Technologies, 14(1), 21-39.

Piscitelli, A. (2009). Nativos digitales. Dieta cognitiva, inteligencia colectiva y arquitectura de la participación. Buenos Aires: Santillana.

Rajewsky, I. (2005). Intermediality, Intertextuality, and Remediation: A Literary Perspective on Intermediality [Intermedialidad, intertextualidad y remediar: una perspectiva literaria en intermedialidad]. Intermédialités, 1(6), 43-64. Recuperado de http://cri.histart.umontreal.ca/cri/fr/intermedialites/p6/pdfs/p6_rajewsky_text.pdf

Rodríguez, J. A. (2009). Sueños digitales de un escritor: la convergencia digital al servicio del ejercicio literario. Signo y Pensamiento, 28(54), 131-143.

Saavedra Galindo, A. (enero-junio de 2017). Los nombres de la realidad. Autoficción en Formas de volver a casa. La Palabra, (30). 
Scheaffer, J. M. (2002). ¿Por qué la ficción? Madrid: Lengua de trapo.

Scolari, C. (2013). Narrativas transmedia: cuando todos los medios cuentan. Barcelona: Deusto.

Serres, M. (1994). Atlas. Madrid: Cátedra.

Skains, R. L. (2017). The Adaptive Process of Multimodal Composition: How Developing Tacit Knowledge of Digital Tools Affects Creative Writing. Computers and Composition, 43, 106-117.

Vélez Correa, R. (s.f.). Misterios y encantos de la intertextualidad. Manizales: Universidad de Caldas 
